\title{
Prevention of hypokalaemia in bulimia nervosa
}

\author{
Leanne Barron ${ }^{1,2^{*}}$, Warren Ward ${ }^{3}$ \\ From 2015 ANZAED Conference: Riding the Waves to Recovery \\ Surfers Paradise, Australia. 21-22 August 2015
}

Hypokalaemia represents a significant risk factor for sudden cardiac death in patients with bulimia nervosa. Whilst the goal of treatment is always reduction of vomiting, this may not be easily attainable and in the interim some patients may be at significant risk.

As a harm minimisation strategy, it was suggested that Nexium (esomeprazole) could reduce hypokalemia. This is a logical manoeuvre in view of the mechanism for potassium depletion being renal compensation for hydrogen loss in the vomitus.

After discussion with their treating psychiatrist, two patients who had required intensive potassium repletion (including via ICU and PIC lines) were commenced on a low dose of Nexium as outpatients. ECGs were monitored (particularly as Nexium may prolong the QT interval). Potassium supplements were continued, and electrolytes were monitored daily initially.

Despite both patients continuing to binge/purge at similar frequency, their potassium levels remained at levels in the low end of normal range. Neither patient required intravenous potassium, although levels did fall intermittently (when patients omitted doses of Nexium). Both commented that they felt they "didn't deserve" such an effective treatment, but eventually their compliance improved. Unfortunately one patient later developed QT prolongation and the nexium had to be discontinued. However, commencement of ranitidine is currently underway on the assumption that this will similarly reduce hydrogen and hence potassium loss. Nexium is known to cause prolonged QT, and this is a risk for which patients would need to be monitored medically with regular ECGs. It remains to be seen whether ranitidine is similarly effective in preventing hypokalaemia. If this is indeed the case it may prove a safer option.

* Correspondence: leannejbarron@gmail.com

${ }^{1}$ QUT Eating Disorder Clinic, Brisbane, Australia

Full list of author information is available at the end of the article
Authors' details

'QUT Eating Disorder Clinic, Brisbane, Australia. ${ }^{2}$ Brisbane City Doctors, Brisbane, Australia. ${ }^{3}$ Royal Brisbane Women's Hospital, Brisbane, Australia.

Published: 23 November 2015

doi:10.1186/2050-2974-3-S1-061

Cite this article as: Barron and Ward: Prevention of hypokalaemia in bulimia nervosa. Journal of Eating Disorders 2015 3(Suppl 1):O61.

Submit your next manuscript to BioMed Central and take full advantage of:

- Convenient online submission

- Thorough peer review

- No space constraints or color figure charges

- Immediate publication on acceptance

- Inclusion in PubMed, CAS, Scopus and Google Scholar

- Research which is freely available for redistribution

Submit your manuscript at www.biomedcentral.com/submit

\section{() Biomed Central}

